\title{
Image Recognition Method for Defect on Coke with Low-quality Coal
}

\author{
Yasuhiro SAITO, (1)* Tetsuya KANAI, ${ }^{10}$ Daisuke IGAWA, ${ }^{1)}$ Yukinori MIYAMOTO, ${ }^{11}$ Shohei MATSUO, ${ }^{11}$ \\ Yohsuke MATSUSHITA, ${ }^{1)}$ Hideyuki AOKI, ${ }^{1)}$ Seiji NOMURA, ${ }^{2)}$ Hideyuki HAYASHIZAKI') and Shigeto MIYASHITA ${ }^{3)}$ \\ 1) Graduate School of Engineering, Tohoku University, 6-6-07 Aoba, Aramaki, Aoba-ku, Sendai, Miyagi, 980-8579 Japan. \\ 2) Process Research Laboratories, Nippon Steel \& Sumitomo Metal Corp., 20-1 Shintomi, Futtsu, Chiba, $293-8511$ Japan. \\ 3) Kashima Works, Nippon Steel \& Sumitomo Metal Corp., 3 Hikari, Kashima, Ibaraki, 314-0014 Japan.
}

(Received on May 15, 2014; accepted on June 18, 2014)

\begin{abstract}
The image recognition method was proposed to quantify non-adhesion grain boundaries which were considered as a factor of coke strength besides pores, and the correlation between coke strength and the amount of defects evaluated by the method was investigated in comparison with the one by the marking method. Coke with low-quality coal was fractured by a diametral-compression test, and the fracture crosssections were observed by a scanning electron microscopy (SEM) and a 3D laser scanning microscope (LSM). The marking method and image recognition method were applied to SEM and LSM images, respectively. As a result, the fracture strength measured by the diametral-compression test was linearly decreased with an increase in blending ratio of low-quality coal. In the marking method, most non-adhesion grain boundaries were not detected up to $50 \%$ in the blending ratio, and the boundaries increased sharply from 50 to $100 \%$ in the blending ratio. On the other hand, in the recognition method, the defects which were composed of both pores and non-adhesion grain boundaries, increased linearly with the blending ratio, and the amount of defects corresponded to coke strength. Therefore, the image recognition method is expected as the quantification technique of defects decreasing coke strength.
\end{abstract}

KEY WORDS: ironmaking; coke; low-quality coal; non-adhesion grain boundary.

\section{Introduction}

Coke serves as a spacer sustaining the flow passes of liquid metal and reducing gas in a blast furnace, and coke strength is a key feature of coke. Recently, due to the rising price and depletion of metallurgical coals, coke production from low-quality coal has been required. However, the strength of the coke from low-quality coal is not enough high, and it is necessary to identify the dominant factor decreasing the coke strength.

Coke, which is generally made from caking coal is a porous material, and the coke strength of this kind is determined by the pore structure rather than the hardness of coke matrix. ${ }^{1)}$ Over the past few decades, cross-sectional observations of coke have been conducted to correlate the coke strength with pore structure. Patrick and Stacey ${ }^{2)}$ calculated the porosity of coke from the polished surface of coke using a microscope and demonstrated that coke strength decreased with an increase in porosity. Hiraki et al. ${ }^{3)}$ observed ground surfaces of coke from caking coal by an optical microscope. The section was classified into pores and coke matrix on the basis of the difference in brightness, and structure parameters (e.g., porosity, wall thickness, and pore roundness) were evaluated. They reported that coke with high porosity, low

\footnotetext{
* Corresponding author: E-mail: saito@tranpo.che.tohoku.ac.jp DOI: http://dx.doi.org/10.2355/isijinternational.54.2512
}

roundness pores and thin pore wall was low in strength. The strength of coke from caking coal is high because the coal particles adhere to each other during carbonization, and the strength is mainly determined by pore structure. On the other hand, Arima ${ }^{4)}$ observed the polished surface of coke made from low-quality coal by an optical microscopy and reported that the defect defined as non-adhesion grain boundaries was formed. Therefore, the dominant factor of the strength of coke from low-quality coal would be not only pore structure but also non-adhesion grain boundary.

Nomura and Arima ${ }^{5)}$ focused on the relationship between coke strength and the total dilatation of coals and concluded that the strength of coke from low-quality coal was low due to low dilatation property of low-quality coal. Kubota et al. ${ }^{6}$ ) classified the microscopic photograph of the polished surface of coke from low-quality coal into pores and coke matrices based on the difference in brightness. They explained that the region of pores with low roundness below 0.2 increased with a rise in the ratio of slightly caking coal and suggested that the pores with the roundness below 0.2 were liable to be an origin of fracture. Since non-adhesion grain boundaries exist in the interface of coal particles as Arima ${ }^{4)}$ pointed out, non-adhesion grain boundaries may be contained in the pore with circularity lower than 0.2 as shown by Kubota et al. Saito et al. ${ }^{7}$ performed fracture analyses for the coke models including coke matrices, pores and non-adhesion grain boundaries using the rigid bodies- 
spring model and demonstrated that the strength of the model coke decreased with the existence ratio of the non-adhesion grain boundaries. For the reasons mentioned above, nonadhesion grain boundaries would decrease the coke strength, and the necessity of quantification of non-adhesion grain boundaries has grown. Kanai et al. ${ }^{8)}$ observed the fracture cross-section of coke by a diametral-compression test and extracted non-adhesion grain boundaries by visual assessment and then investigated the correlation between coke strength and non-adhesion grain boundaries. However, the marking method requires a huge effort, and the result of the method would be dependent on an observer.

In this paper, we propose an image recognition method to investigate a quantitative approach to identify the non-adhesion grain boundary automatically independent of a measurer, and the correlation between coke strength and the amount of defect evaluated by the method is examined and compared with the one by the marking method. ${ }^{8)}$ Coke from caking coal blended with low-quality coal is fractured by a diametral-compression test, and the fracture surfaces are observed by a scanning electron microscopy (SEM) and a 3D laser scanning microscope (LSM). For SEM images, the marking method is used to extract non-adhesion grain boundaries with visual examination. For LSM images, the image recognition method is applied, and the fracture surfaces were classified into pores, coke matrix and nonadhesion grain boundaries with brightness and surface roughness. Moreover, the relationship of the coke strength and existence ratio of the defect is discussed.

\section{Method}

\subsection{Coke Sample and Diametral-compression Test}

Table 1 shows the material properties of caking coal and low-quality coal used as raw materials. The caking coal and low-quality coal were blended and the blending ratio of lowquality coal was 0,50 , and $100 \%$, respectively. The bulk density of coal particles was $0.8 \mathrm{dry}-\mathrm{g} / \mathrm{cm}^{3}$ and the particle size was $<1 \mathrm{~mm}$. To produce coke, the packed bed of coal particles was carbonized from room temperature to $1273 \mathrm{~K}$ with heating rate of $3 \mathrm{~K} / \mathrm{min}$ and at temperature of $1273 \mathrm{~K}$ for $30 \mathrm{~min}$ by heating on the both sides in the coke oven. Then, the coke was adjusted in the cylindrical specimen with $10 \mathrm{~mm}$ in both diameter and height, respectively. Diametralcompression tests were performed for the samples by a universal tester (Shimadzu Co., Autograph AG-150 kN) and the tensile strength of coke was evaluated by the Weibull plot.

\subsection{Quantitative Evaluation of Non-adhesion Grain Boundaries}

In the previous study, ${ }^{8)}$ it has been known that there are the pores, fractured coke matrices and non-adhesion grain

Table 1. Characterization of coals. ${ }^{8)}$

\begin{tabular}{lcccccc}
\hline & \multicolumn{3}{c}{$\begin{array}{c}\text { Elemental analysis } \\
\text { results [daf.\%] }\end{array}$} & Ro & $\begin{array}{c}\text { log } \\
\text { (MF/ddpm) }\end{array}$ & TD \\
& $\mathrm{C}$ & $\mathrm{H}$ & $\mathrm{O}$ & {$[\%]$} & {$[-]$} & {$[\%]$} \\
\hline Caking coal & 90.3 & 5.1 & 2.1 & 1.20 & 3.08 & 86 \\
Low-quality coal & 84.6 & 5.9 & 7.3 & 0.78 & 1.38 & 0 \\
\hline
\end{tabular}

boundaries on the fracture surface of coke from low-quality coal. Hayashizaki et al. performed an image analysis for the polished surface of coke and the pores were extracted according to the difference in brightness because the pore had depth and its brightness was dark. ${ }^{9)}$ In addition, the fracture surface of coke matrix is smooth because coke matrix is the surface caused by fracture. In contrast, the surface of non-adhesion grain boundary is rough because the shape of coal grain is maintained. In the present study, non-adhesion grain boundaries were quantified by different two kinds of methods in consideration of these features.

\subsubsection{Observation of Fracture Surface of Coke by SEM and Marking Method ${ }^{8)}$}

The fracture cross-section of coke obtained by the diametral-compression test was observed using a scanning electron microscope (SEM: KEYENCE Co., VE8800) at $1.7 \mathrm{kV}$ in accelerating voltage, and the SEM images with resolution of $1280 \times 960$ pixels $(0.96 \mu \mathrm{m} /$ pixel $)$ were acquired. In the marking method, ${ }^{8}$ rough faces on the SEM image were identified as non-adhesion grain boundaries by sight and the region was filled with pure white ( 255 in gray scale) by an image editing software (Paint, Microsoft). Then, the number of the pixels with a value of 255 was counted up and the area of non-adhesion grain boundaries was measured. The area of non-adhesion grain boundaries was normalized by the total area of the image and the existence ratio of the boundaries was calculated.

\subsubsection{Observation of Fracture Surface of Coke by LSM and Image Recognition Method}

The coke surface prepared by the diametral-compression test was observed using a 3D laser scanning microscope (LSM: KEYENCE Co., VK-X210), and the cross-sectional image and surface texture of coke were obtained. The images with resolution of $1024 \times 768$ pixels were connected with peripheral images and the graphics of $1920 \times 1420$ pixels were acquired. The resolution was $687.8 \mathrm{~nm} /$ pixel and 500 $\mathrm{nm}$ in horizontal and vertical directions, respectively.

In the proposed image recognition method, the dark parts in the LSM image were identified as the pores, the rough parts excluding the pores were classified as non-adhesion grain boundaries, and the other ones were as coke matrices. Figure 1 shows the flowchart of the image recognition method. First, the threshold of the luminosity value was set

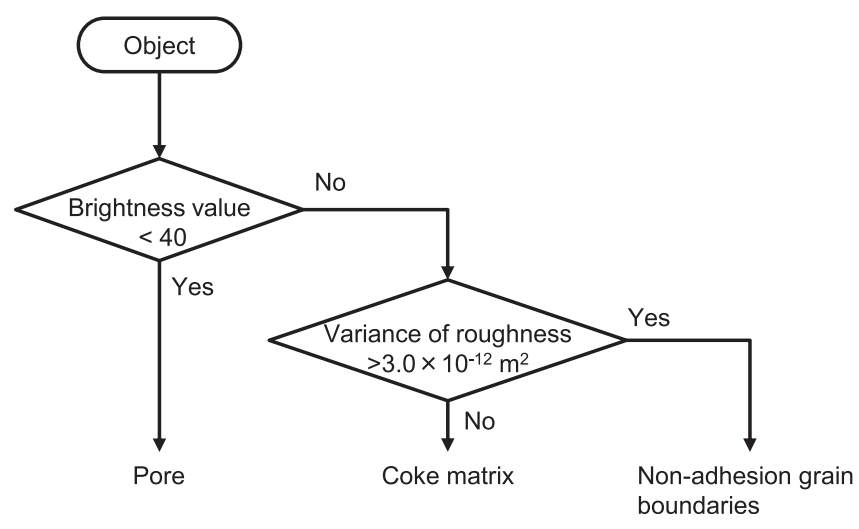

Fig. 1. Flowchart of image recognition method for fracture crosssection. 
to 40 , and the pixels with the brightness value less than the threshold one were classified as pores. Then, to evaluate the roughness, the large-scale waviness profile on the cross-section as shown in Fig. 2 was removed. The $5 \times 5$ Gaussian filter described in Eq. (1) is applied to the raw profile data:

$$
f(x, y)=\frac{1}{2 \pi \sigma^{2}} \exp \left(-\frac{x^{2}+y^{2}}{2 \sigma^{2}}\right),
$$

where $\sigma$ was 1.0 . It seems probable that the amplitude in height direction is small in the portion of coke matrices and the one in the part of non-adhesion grain boundaries is large. Therefore, to evaluate the variation in the amplitude of roughness statistically, the threshold of the variance in height direction was introduced as the following equation:

$$
s^{2}=\frac{1}{n} \sum_{i=1}^{n}\left(x_{i}-\mu\right)^{2},
$$

where the measurement area was $10 \times 10$ pixels, and the threshold was $3.0 \times 10^{-12} \mathrm{~m}^{2}$, respectively. In other words, if the standard deviation of surface roughness was larger than $1.73 \mu \mathrm{m}$, the parts were classified as non-adhesion grain boundaries. The areas of pores, non-adhesion grain boundaries and coke matrices were measured. Then, the areas were normalized by the total area of the image and each existence ratio was obtained.

\section{Results and Discussion}

3.1. Coke Strength with Blending of Low-quality Coal

Figure 3 shows the tensile strength of coke by the diame-
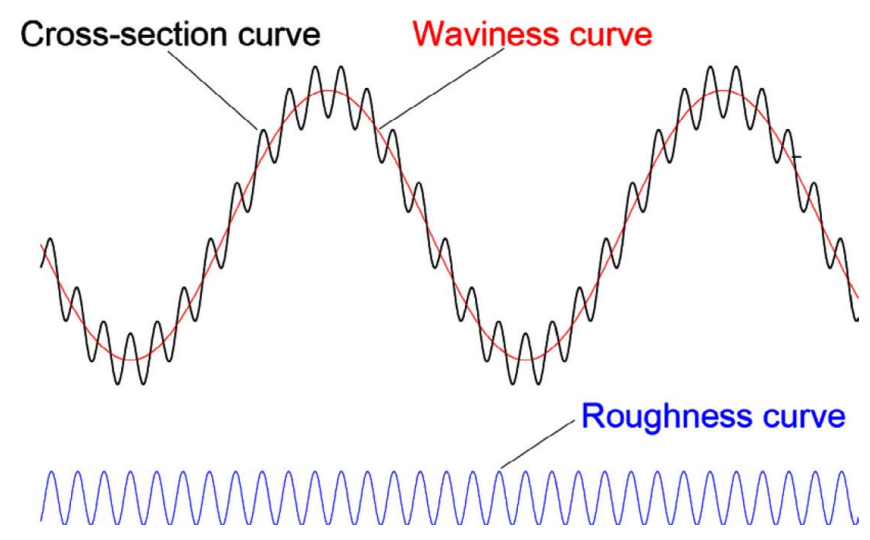

Fig. 2. Image of roughness and waviness. (Online version in color.)

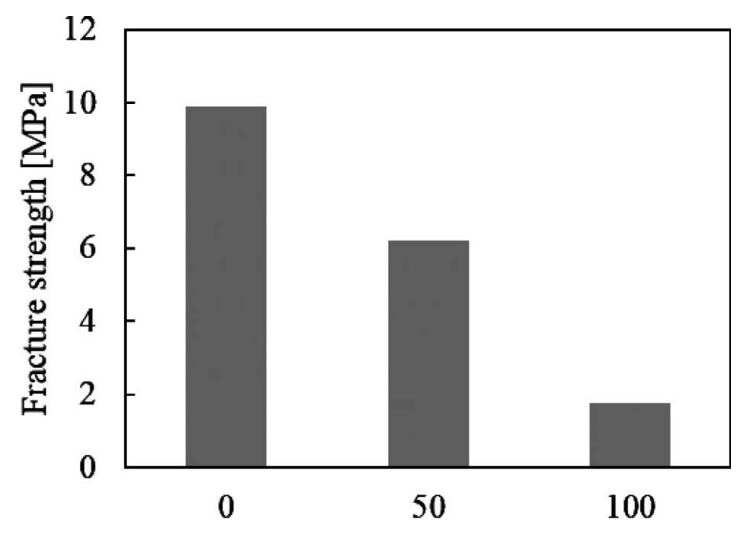

Blending ratio of low-quality coal [mass\%]

Fig. 3. Fracture strength of coke with low-quality coal. tral-compression test. The fracture strength was linearly decreased with an increase in blending ratio of low-quality coal. It has been indicated that the dominant factor of coke strength is the pore structure because coke is a porous material. ${ }^{1)}$ Coke with low-quality coal has non-adhesion grain boundaries, ${ }^{4)}$ and Saito et al. reported that the fracture strength decreased with an increase in blending ratio of lowquality coal with numerical simulation." Therefore, the increases of pores and non-adhesion grain boundaries would decrease the strength of coke with low-quality coal.

\subsection{Quantitation of Non-adhesion Grain Boundaries}

\subsubsection{Marking Method}

Non-adhesion grain boundaries were quantified by the marking method. Figure 4 shows SEM images of fracture surface of coke whose blending ratio of low-quality coal is 0,50 and $100 \%$. The fracture surface of coke is almost smooth up to $50 \%$ in blending ratio, and the surface is rough in case of $100 \%$ in blending ratio. For example, as shown
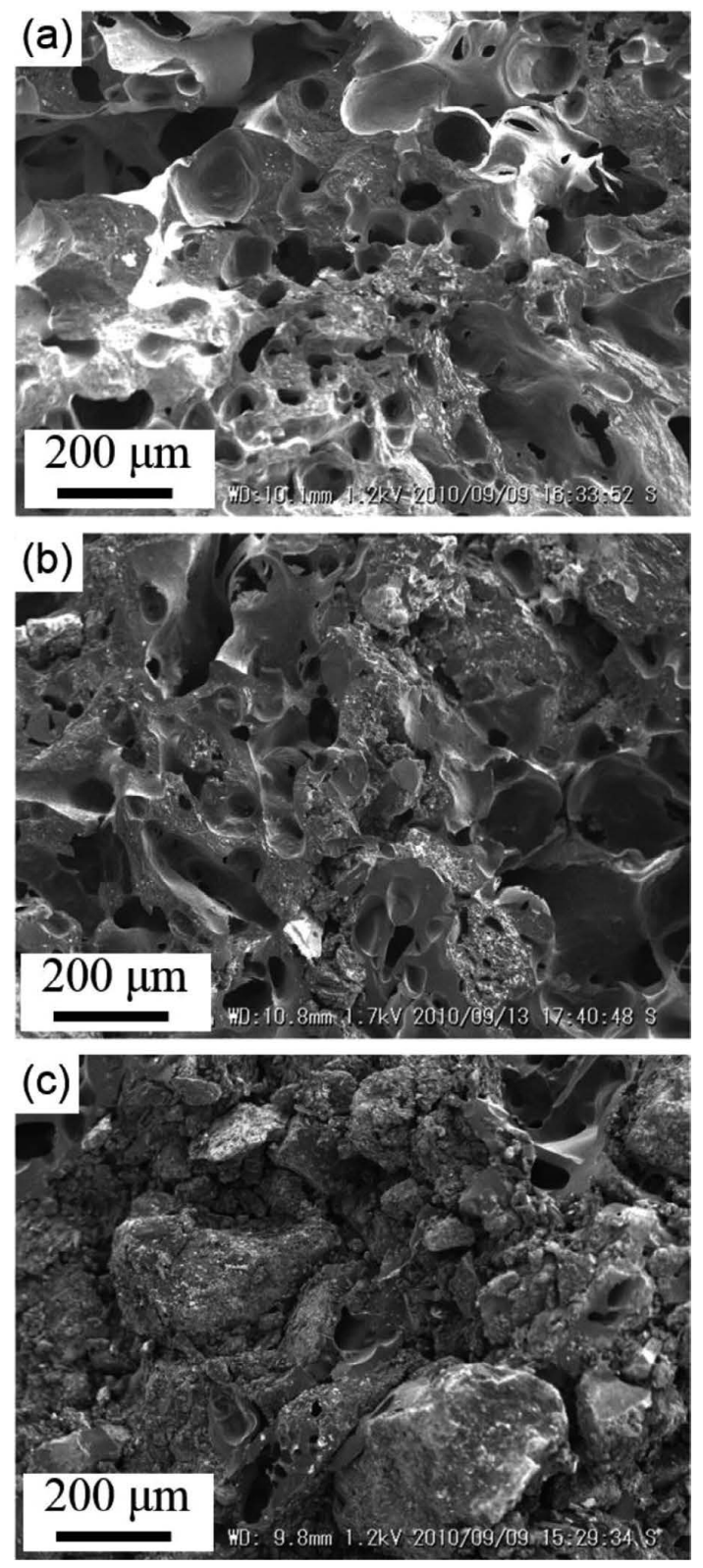

Fig. 4. SEM images of fracture cross-section of coke: ${ }^{8)}$ (a) Lowquality coal is $0 \%$, (b) $50 \%$, and (c) $100 \%$. 


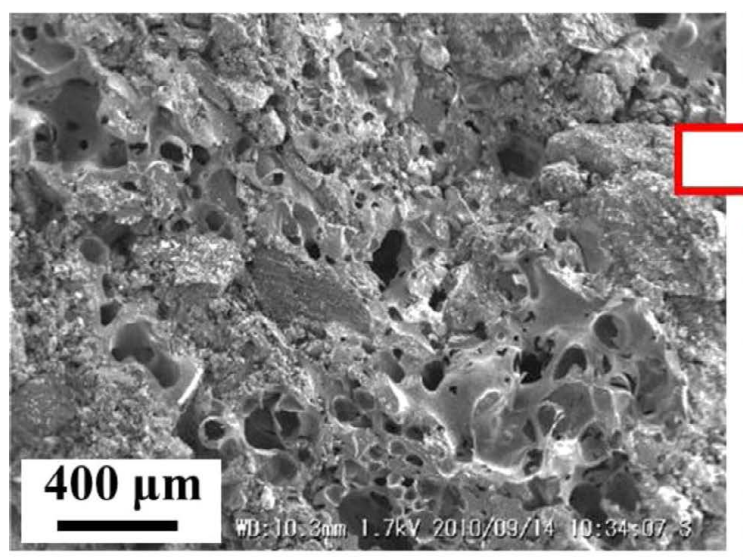

(a) Before marking

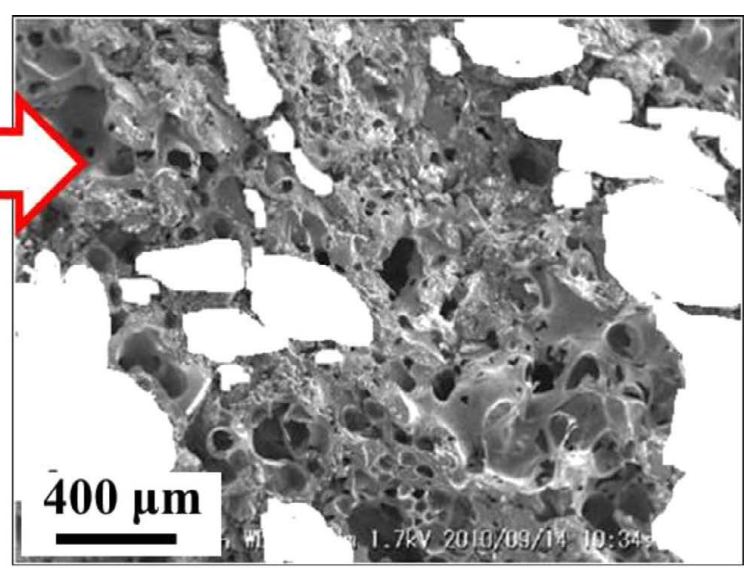

(b) After marking

Fig. 5. Marking method for SEM image (75\% of low-quality coal). ${ }^{8)}$ (Online version in color.)

Table 2. Result of marking method.

\begin{tabular}{cc}
\hline $\begin{array}{l}\text { Blending ratio of } \\
\text { low-quality coal [\%] }\end{array}$ & $\begin{array}{l}\text { Existence ratio of non-adhesion } \\
\text { grain boundaries [\%] }\end{array}$ \\
\hline 0 & 0.0 \\
50 & 6.0 \\
100 & 69 \\
\hline
\end{tabular}

in Fig. 5(a), the marking process was conducted for the fracture cross-section in case of $75 \%$ in blending ratio, and marked results as shown in Fig. 5(b) were obtained. ${ }^{8)}$ Nonadhesion grain boundaries were quantified for fractured coke surface with $0,50,100 \%$ in the blending ratio, and then the existence ratio of non-adhesion grain boundaries was acquired as shown in Table 2. When the blending ratio of low-quality coal was $0 \%$, there were no non-adhesion grain boundaries, and there were also few boundaries with the blending ratio of $50 \%$. In contrast, the boundaries increased sharply in case of $50 \%$ in the blending ratio. Therefore, although the marking method qualitatively expressed the increasing trend of non-adhesion grain boundaries with the blending ratio of low-quality coal, the non-adhesion grain boundaries had little correlation with coke strength which decreased linearly. Moreover, these results would rely on an observer and the marking method required a huge effort because non-adhesion grain boundaries were identified by visual assessment. Consequently, an automated image analysis without artifact is essential for the quantification of the non-adhesion grain boundaries.

\subsubsection{Image Recognition Method}

Non-adhesion grain boundaries were quantified by the image recognition method. Figure 6 shows LSM images of fracture cross-section of coke whose blending ratio of lowquality coal is 0,50 and $100 \%$. The texture of cross-section varies with the blending ratio of low-quality coal as in SEM images. The image of coke from caking coal (i.e., $0 \%$ in the blending ratio of low-quality coal) was smooth, and the one of coke from low-quality coal (i.e., $100 \%$ in the blending rate) was textured. First, the recognition method was applied to the LSM image with $0 \%$ in the ratio shown in Fig. 7(a). Figure 7(b) shows the pores and the others were classified by brightness from Fig. 7(a). The result clearly shows that
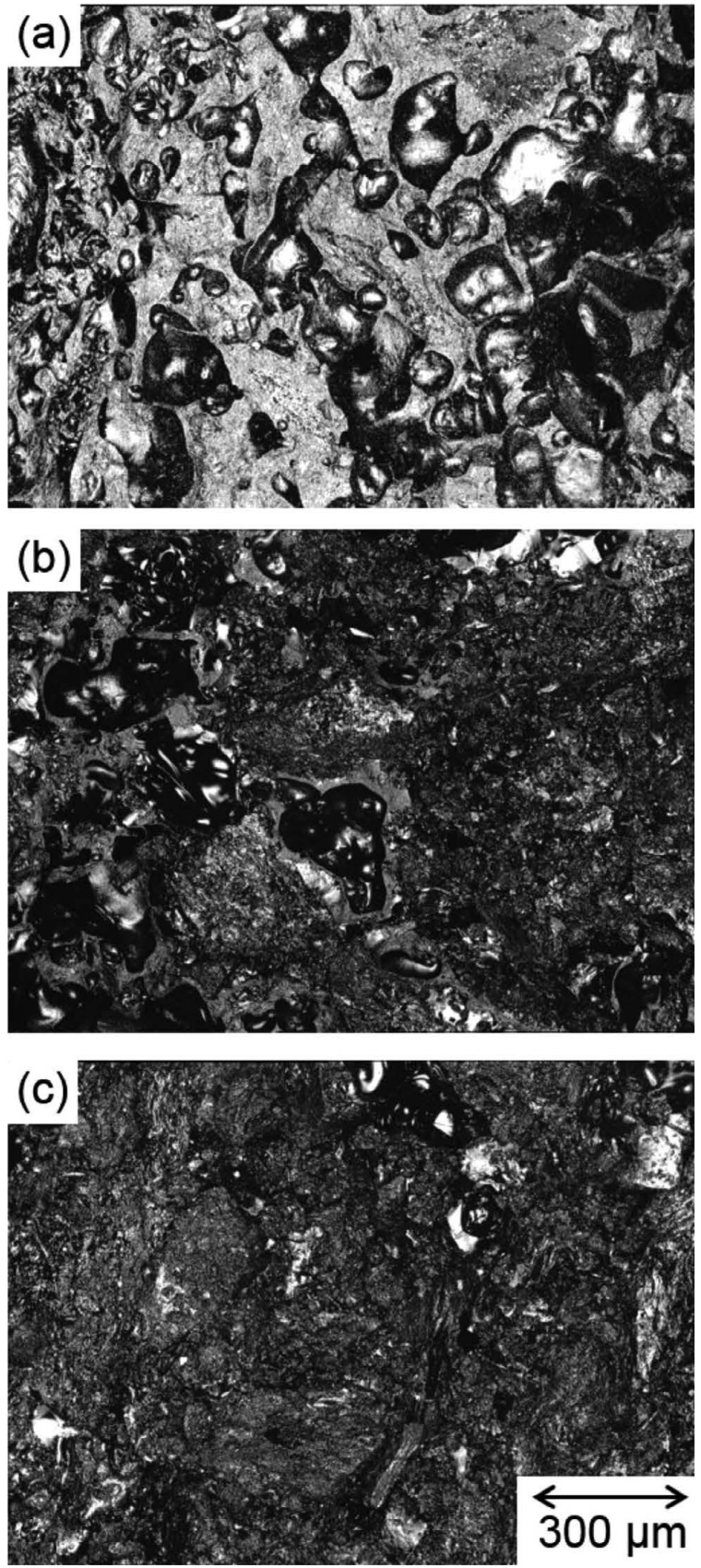

Fig. 6. LSM images of fracture cross-section of coke: (a) Lowquality coal is $0 \%$, (b) $50 \%$, and (c) $100 \%$. 


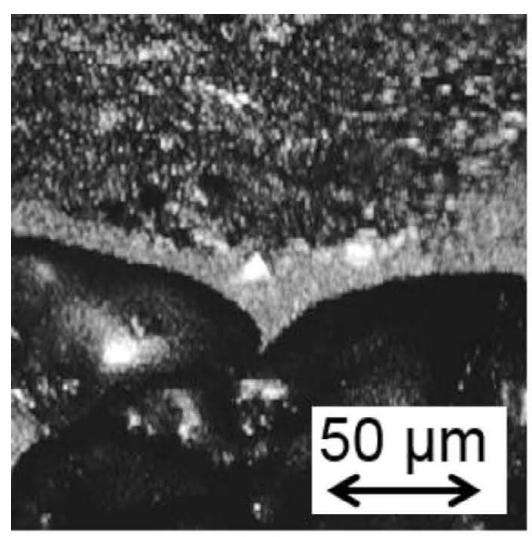

(a)

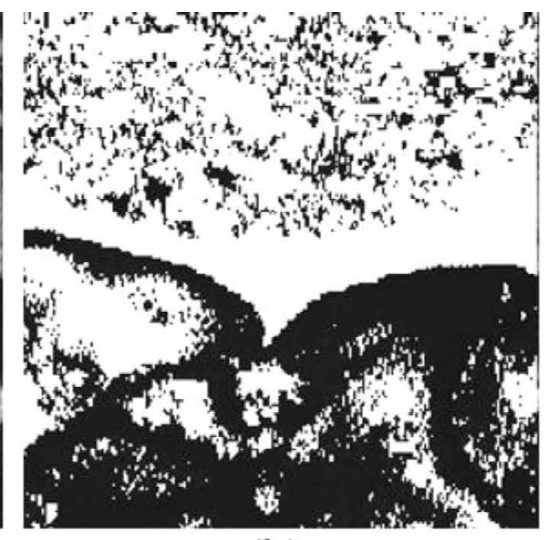

(b)

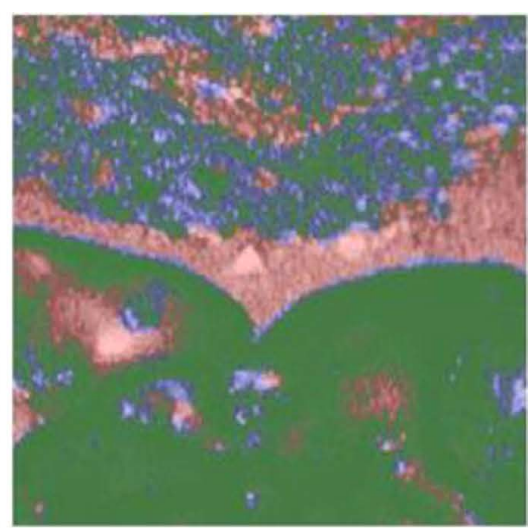

(c)

Fig. 7. Image recognition method for LSM images: (a) Original cross-section geometry, (b) pore (black part) and other (white part) which were determined by brightness values, and (c) non-adhesion grain boundaries (blue part) and coke matrix (pink part) which were determined by roughness values, and pore (green part). (Online version in color.)

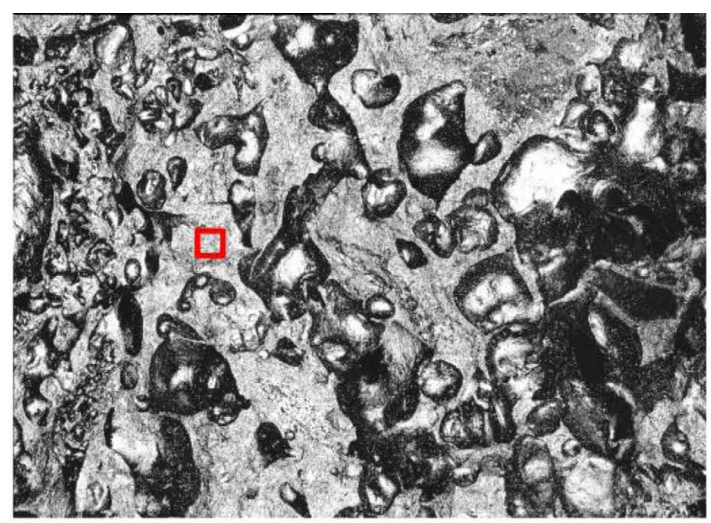

(a)

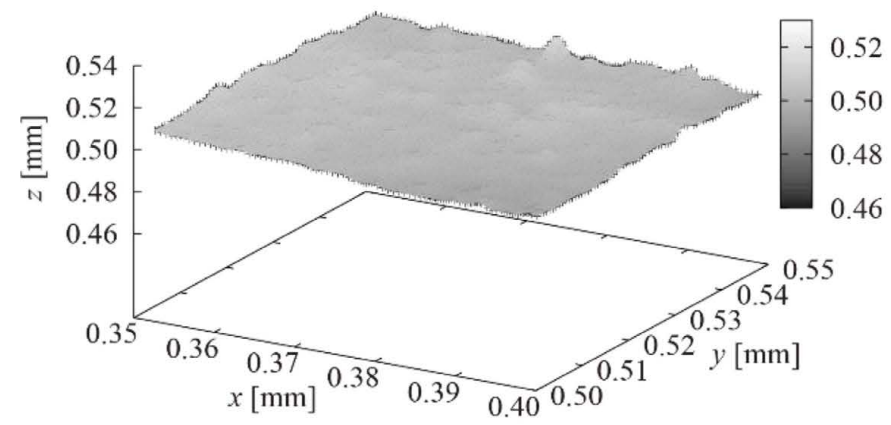

(c)

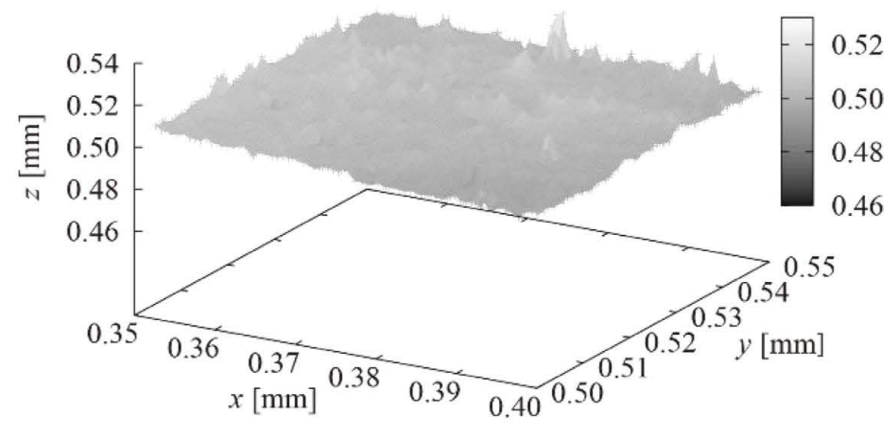

(b)

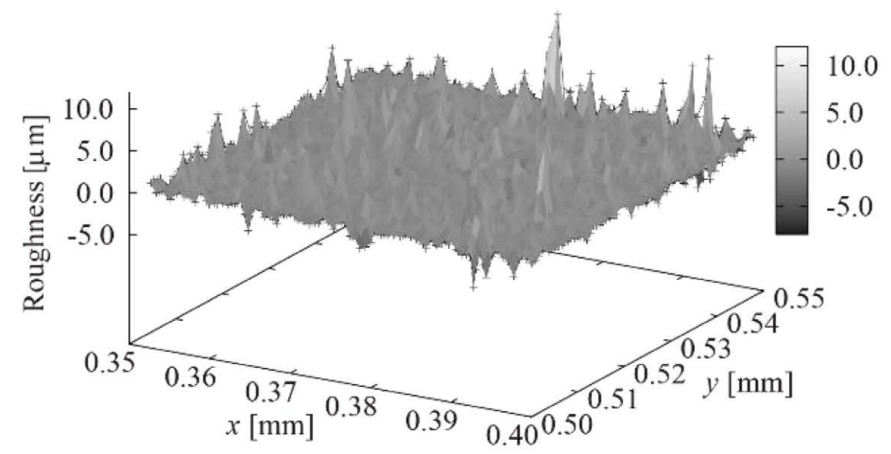

(d)

Fig. 8. Laser scanning microscope (LSM) image and filtration operator applied to a surface: (a) Cross-sectional geometry, and (b) the real surface in red region of (a), (c) Gaussian filtered surface, and (d) roughness components. (Online version in color.)

the characteristic pore in the lower part of Fig. 7(a) can be captured. Next, to evaluate surface roughness, the filter operation indicated in Fig. 8 was carried out. Figure 8(a) shows the LSM image of $0 \%$ in the blending ratio of lowquality coal. The real surface shown in Fig. 8(b) was obtained from a part of Fig. 8(a). A Gaussian filter given by Eq. (1) was applied to the real surface, and the undulation shown in Fig. 8(c) was calculated. Then, roughness was only extracted by removal of the undulation in Fig. 8(c) from the surface shown in Fig. 8(b). The parts excluding the pores in Fig. 7(a) were classified by roughness, and the identified result was acquired as shown in Fig. 7(c). The non-adhesion grain boundaries, matrices, and pores on the fracture surface can be recognized by the above method.

Figure 9 shows the classified fracture cross-section of coke with 0,50 , and $100 \%$ in the blending ratio of low-quality coal by the image recognition method. This result indicates that non-adhesion grain boundaries can be successfully extracted from LSM images of Fig. 2. The classification is then evaluated quantitatively. Table 3 lists the existence ratio distin- 

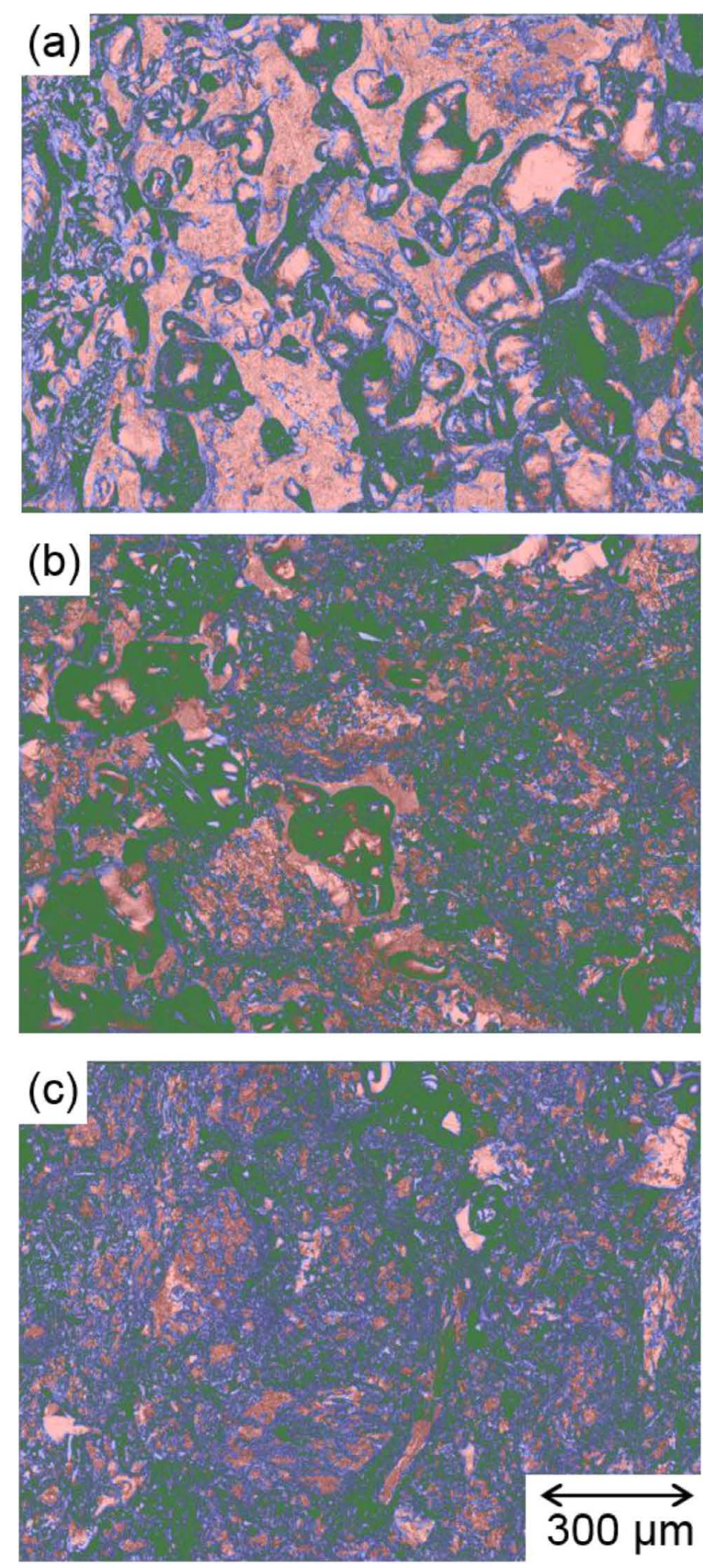

Fig. 9. Recognized fracture cross-section of coke (blue part: nonadhesion grain boundaries, pink part: coke matrix, green part: pore): (a) Low-quality coal is $0 \%$, (b) $50 \%$, and (c) $100 \%$. (Online version in color.)

guished with the luminosity value (i.e., pores and the others). The existence ratio of pores increased and then decreased with an increase in the blending ratio of low-quality coal. Hence, there was not clear association between the blending ratio and existence ratio of pores. It is difficult to resolve the variation of coke strength with an increase in the blending ratio only by the evaluation of brightness (e.g., Hayashizaki et $a l .^{9)}$ ), which is one of the image analyses. The parts excluding the pores were classified into the non-adhesion grain boundaries and matrices by surface roughness, and the classified results listed in Table 4 were obtained. In respect of non-adhesion grain boundaries, the existence ratio of non-adhesion grain boundaries decreased and then increased with an increase in the blending ratio of low-quality coal. From the results, the blending ratio of low-quality coal was
Table 3. Classification based on brightness in image recognition method.

\begin{tabular}{ccc}
\hline $\begin{array}{l}\text { Blending ratio of } \\
\text { low-quality coal [\%] }\end{array}$ & $\begin{array}{l}\text { Existence ratio of } \\
\text { pore [\%] }\end{array}$ & $\begin{array}{l}\text { Existence ratio of } \\
\text { other [\%] }\end{array}$ \\
\hline 0 & 21 & 79 \\
50 & 41 & 59 \\
100 & 27 & 73 \\
\hline
\end{tabular}

Table 4. Classification based on variance of roughness in image recognition method.

\begin{tabular}{cccc}
\hline $\begin{array}{l}\text { Blending ratio } \\
\text { of low-quality } \\
\text { coal [\%] }\end{array}$ & $\begin{array}{l}\text { Existence ratio } \\
\text { of pore [\%] }\end{array}$ & $\begin{array}{l}\text { Existence ratio of } \\
\text { coke matrix [\%] }\end{array}$ & $\begin{array}{l}\text { Existence ratio of } \\
\text { non-adhesion grain } \\
\text { boundaries [\%] }\end{array}$ \\
\hline 0 & 21 & 36 & 43 \\
50 & 41 & 26 & 33 \\
100 & 27 & 18 & 55 \\
\hline
\end{tabular}

Table 5. Result of image recognition method.

\begin{tabular}{ccc}
\hline $\begin{array}{l}\text { Blending ratio of } \\
\text { low-quality coal [\%] }\end{array}$ & $\begin{array}{l}\text { Existence ratio of } \\
\text { coke matrix [\%] }\end{array}$ & $\begin{array}{l}\text { Existence ratio of } \\
\text { defect [\%] }\end{array}$ \\
\hline 0 & 36 & 64 \\
50 & 26 & 74 \\
100 & 18 & 82 \\
\hline
\end{tabular}

poorly correlated with the existence ratio of the boundaries. This is caused by the classification of pores and non-adhesion grain boundaries, and it appears that the parts with the large standard deviation of roughness affect the evaluation of brightness. Therefore, in consideration of the non-adhesion grain boundaries judged as pores, not only the boundaries but pores were regarded as defects, and Table 4 was replaced to the result shown in Table 5. The result indicates that the increasing trend of the amount of defects with the blending ratio, and the defect is well correlated with the blending ratio. In regard to coke strength, the coke strength decreasing linearly related to the amount of defects which decreased linearly. Hence, the change in the amount of defects can be captured by classifying pores with brightness and non-adhesion grain boundaries on the basis of surface roundness.

In the present study, it is demonstrated that the amount of non-adhesion grain boundaries was estimated by the marking method, and the defects were quantified by the image recognition method. In the marking method, non-adhesion grain boundaries were not detected up to $50 \%$ in blending ratio of low-quality coal, and the boundaries increased sharply with $100 \%$ in blending ratio. The non-adhesion grain boundaries identified by the marking method had little correlation with coke strength which linearly decreased with an increase in the blending ratio of low-quality coal. Moreover, since these results can be dependent on an observer, when the measurer is different, the results would change. On the other hand, although the image recognition method requires a few input parameters for quantifying non-adhesion grain boundaries, it was demonstrated that the fracture cross-section of coke can be classified by clear indexes unlike the marking method. The defects detected by the 
image recognition method increased linearly with the blending ratio of low-quality coal, and the defects were successfully correlated to coke strength which linearly decreased with an increase in the blending ratio.

\section{Conclusion}

In the present study, the image recognition method was proposed to quantify non-adhesion grain boundaries which were considered as a factor of coke strength besides pores, the correlation of coke strength and the amount of defects evaluated by the method was investigated in comparison with the ones by the marking method. Coke from low-quality coal was fractured by the diametral-compression test, and the fracture surfaces were observed by the scanning electron microscopy (SEM) and 3D laser scanning microscope (LSM), respectively. The marking method was applied to SEM images to quantify non-adhesion grain boundaries, and the image recognition method was applied to LSM images to evaluate defects which were composed of pores and non-adhesion grain boundaries. The fracture strength linearly decreased with an increase in blending ratio of low-quality coal. In the marking method, non-adhesion grain boundaries were not detected up to $50 \%$ in blending ratio of low-quality coal, and the boundaries increased sharply with $100 \%$ in blending ratio. On the other hand, in the recognition method, the amount of defects increased linearly with the blending ratio, and the amount of defects successfully corresponded to coke strength. For the reasons mentioned above, the image recognition method is expected as the quantification technique of defects decreasing coke strength with few human effort by improving the input parameters.

\section{Acknowledgements}

This work has been done in Research Group of Cokemaking
Technology for Low-quality Coals und Unused Carbon Resources in ISIJ (The chief examiner: Prof. H. Aoki, Tohoku Univ.). The authors would like to acknowledge the research group members gratefully.

\section{Nomenclature}

$f$ Gaussian function

$n$ number of observations

$s^{2}$ variance

$x, y, z$ coordinates

$x$ distance from the origin in the horizontal axis

$x_{i} i$ th observations

$y$ distance from the origin in the vertical axis

$\mu$ mean of observations

$\sigma$ standard deviation of the Gaussian distribution [ddpm]

\section{REFERENCES}

1) M. Mihashi, M. Soejima, Y. Asakuma, T. Yamamoto, H. Aoki, T. Miura, K. Kato and S. Itagaki: Tetsu-to-Hagané, 88 (2002), 188.

2) J. W. Patrick and A. E. Stacey: Fuel, 51 (1972), 81.

3) K. Hiraki, H. Hayashizaki, Y. Yamazaki, T. Kanai, X. Zhang, M. Shoji, H. Aoki, T. Miura and K. Fukuda: ISIJ Int., 51 (2011), 538.

4) T. Arima: Tetsu-to-Hagané, 87 (2001), 274.

5) S. Nomura and T. Arima: Fuel, 83 (2004), 1771.

6) Y. Kubota, S. Nomura, T. Arima and K. Kato: ISIJ Int., 51 (2011), 1800 .

7) Y. Saito, S. Matsuo, T. Kanai, A. Toishi, A. Uchida, Y. Yamazaki, Y. Matsushita, H. Aoki, S. Nomura, H. Hayashizaki and S. Miyashita: Tetsu-to-Hagané, 100 (2014), 140.

8) T. Kanai, Y. Yamazaki, X. Zhang, A. Uchida, Y. Saito, M. Shoji, H. Aoki, S. Nomura, Y. Kubota, H. Hayashizaki and S. Miyashita: $J$. Thermal Sci. Tech., 7 (2012), 351.

9) H. Hayashizaki, K. Ueoka, T. Ogata, Y. Yamazaki, Y. Matsushita, H. Aoki, T. Miura, K. Fukuda and K. Matsudaira: Tetsu-to-Hagané, 95 (2009), 460. 